\title{
Aplikasi Bank Materi Pembelajaran untuk Jenjang SMA
}

\author{
Naufal Harits Pratama ${ }^{\mathrm{a} 1}$, Yulianti ${ }^{\mathrm{a} 2}$, Anggi Srimurdianti Sukamto ${ }^{\text {a3 }}$ \\ ${ }^{a}$ Program Studi Informatika Universitas Tanjungpura \\ Jl. Prof. Dr. H. Hadari Nawawi, Pontianak, Kalimantan Barat 78115 \\ ${ }^{1}$ naufal haritspratama@gmail.com \\ ${ }^{2}$ y suanda@yahoo.com \\ 3anggidianti@gmail.com
}

\begin{abstract}
Abstrak
Penelitian ini menjelaskan bagaimana membuat suatu Learning Management System dalam bentuk bank materi yang akan digunakan oleh siswa di jenjang SMA. Metode pembelajaran yang digunakan pada kurikulum pendidikan di Indonesia saat ini selain proses belajar mengajar secara langsung adalah siswa yang dituntut untuk mandiri mencari informasi dan materi dari sumber lain yang tidak terbatas pada buku cetak. Oleh sebab itu, perlu untuk menyediakan aplikasi dimana siswa dapat mengakses materi-materi pembelajaran secara terintegrasi dan secara menyeluruh. Aplikasi menyediakan semua materi pembelajaran yang dibutuhkan oleh siswa untuk menunjang jalannya proses pembelajaran. Sehingga mempermudah siswa dalam mengakses materi pembelajaran yang hanya menggunakan akses ke tempat yang terpusat. Aplikasi bank materi pembelajaran untuk jenjang SMA yang dibangun merupakan bagian dari Learning Management System dan memiliki bentuk sebagai bank materi. Usability Testing merupakan cara pengujian produk langsung ke pengguna tanpa memberi tahu cara produk tersebut bekerja, kemudian akan dilakukan wawancara menggunakan kuesioner dengan aspek Usability. Hasil uji usability yang didapat menunjukkan bahwa guru dan siswa yang menggunakan aplikasi menganggap bahwa aplikasi dapat mempermudah proses pembelajaran.
\end{abstract}

Kata kunci: Learning Management System, bank materi, kurikulum, materi pembelajaran, usability testing

\section{Application for Learning Materials Bank for High School Level}

\begin{abstract}
This research explains how to make a Learning Management System in the form of a material bank that will be used by students at the high school level. Learning methods used in the education curriculum in Indonesia today in addition to the teaching and learning process directly are students who are required to independently seek information and material from other sources that are not limited to printed books. Therefore, it is necessary to provide applications where students can access learning materials in an integrated and comprehensive manner. The application provides all learning materials needed by students to support the course of the learning process. Making it easier for students to access learning material that only uses access to a centralized place. The learning material bank application for the high school level that is built is part of the Learning Management System and has the form as a material bank. Usability Testing is a way of testing products directly to users without telling them how the product works, then interviews will be conducted using a questionnaire with aspects of Usability. The usability test results obtained indicate that teachers and students who use the application assume that the application can facilitate the learning process.
\end{abstract}

Keywords: Learning Management System, material bank, curriculum, learning material, usability testing

\section{PENDAhuluan}

Di era informasi ini, hampir semua hal di dalam kehidupan seseorang telah menggunakan manfaat dari suatu teknologi. Persebaran teknologi tersebut berdampak pada semua kalangan, dari anak-anak hingga orang dewasa, dari lingkungan cakupan kecil hingga lingkungan dengan cakupan lebih luas seperti institusi Pendidikan. Di lingkungan institusi Pendidikan, kemajuan teknologi dapat dimanfaatkan sebagai penunjang kegiatan belajar mengajar, salah satunya adalah menggunakan teknologi internet untuk mendapatkan informasi yang diperlukan secara luas dan lebih lengkap.

Di kurikulum pendidikan sekarang pun siswa dibebaskan oleh guru untuk menjelajah materi pelajaran yang ada baik melalui buku maupun internet agar siswa mampu berpikir lebih mandiri dan fleksibel. Penggunaan teknologi didalam dunia pendidikan merupakan salah satu hal penting dalam mempelajari ilmu pengetahuan. Pendidikan adalah proses pengubahan sikap dan tata laku seseorang atau kelompok orang dalam usaha mendewasakan manusia melalui upaya pengajaran dan 
pelatihan. Pendidikan merupakan suatu kebutuhan bagi manusia agar dapat lebih berkembang ke depan dengan tujuan untuk mencerdaskan. Pendidikan merupakan suatu aktivitas belajar dan mengajar, dimana seorang atau banyak individu belajar dari orang yang lebih tahu agar mendapat pengetahuan. [1]

Profesionalitas guru dalam memilih dan menggunakan metode pembelajaran yang sesuai dengan temaatau pokok bahasan serta dengan memperhatikan minat belajar yang terdapat pada siswa selain faktor-faktor lainnya juga memiliki peran yang tidak kalah penting dalam usaha mengubah hasil belajar siswa yang semula rendah atau dibawah KKM sehingga dapat diusahakan meningkat semaksimal mungkin melampaui KKM. Untuk mengubah hasil belajarsiswa tersebut, seorang guru harus memiliki pengetahuan yang mendalam tentang materi-materi yang akan disampaikan serta mampu mengolah materi dan tepat dalam menggunakan metode pembelajaran menurut Paikem (Pembelajaran aktif, inovatif, kreatif dan menyenangkan) dan tidak kalah penting untuk memperhatikan minat sebagai salah satu faktor penunjang keberhasilan suatu pembelajaran yang hendak dicapai. [2]

\section{URAIAN PENELITIAN}

\section{A. Pendidikan}

Di Indonesia berbagai upaya telah dilakukan oleh pemerintah guna tercapainya cita-cita dalam bidang pendidikan seperti yang diamanatkan oleh pembukaan UUD 1945 yaitu mencerdaskan kehidupan bangsa. Upaya yang dilakukan tersebut berupa pembaharuan atau inovasi dalam bidang pendidikan. Untuk itu pemerintah mengeluarkan kebijakan-kebijakan dalam pendidikan. Kebijakan-kebijakan tersebut tertuang dalam UndangUndang Dasar 1945, program-program, undang-undang, peraturan pemerintah, peraturan menteri, dan sebagainya. Kebijakan-kebijakan tersebut sudah banyak yang dikeluarkan oleh pemerintah, di antara kebijakan itu, ada juga yang berkaitan dengan Inovasi Pendidikan. [3]

Pendidikan merupakan komponen penting dalam meningkatkan taraf hidup masyarakat, sehingga untuk mencapai masyarakat yang berkualitas, sektor pendidikan harus mendapatkan perhatian khusus, untuk menunjang pendidikan formal.[4] Berdasarkan Pasal 1 UU RI No. 20 Tahun 2003 tentang Sistem Pendidikan Nasional, Pendidikan adalah usaha sadar dan terencana untuk mewujudkan suasana belajar dan proses pembelajaran agar peserta didik secara aktif mengembangkan potensi dirinya untuk memiliki kekuatan spiritual keagamaan, pengendalian diri, kepribadian, kecerdasan, akhlak mulia, serta keterampilan yang diperlukan dirinya, masyarakat, bangsa dan negara. [5]

\section{B. Pembelajaran}

Belajar adalah suatu perubahan perilaku yang relatif permanen dan dihasilkan dari pengalaman masa lalu atau pun dari pembelajaran yang bertujuan atau direncanakan. Belajar adalah proses yang kompleks di dalamnya mengandung aspek pengembangan pengetahuan, pengembangan ingatan dan kesadaran, pengembangan pengkayaan makna penafsiran dan realitas, serta pengembangan perilaku dan obsesi keilmiahan. Atas dasar ini lahirlah model pembelajaran berbasis masalah, model pembelajaran kooperatif, model pembelajaran eksploratori, model pembelajaran peningkatan kemampuan berpikir, model pembelajaran suggestopedia, model pendekatan communicative language teaching (CLT), model pembelajaran matematika realistik, model pembelajaran PAKEM (Pembelajaran Aktif, Kreatif, Efektif dan Menyenangkan). Model-model ini digunakan dari berbagai penerapan metode pembelajaran. [6]

\section{Kurikulum}

Kurikulum adalah suatu respon pendidikan terhadap kebutuhan masyarakat dan bangsa dalam membangun generasi muda bangsanya. Secara pedagogis, kurikulum adalah rancangan pendidikan yang memberi kesempatan untuk peserta didik mengembangkan potensi dirinya dalam suatu suasana belajar yang menyenangkan dan sesuai dengan kemampuan dirinya untuk memiliki kualitas yang diinginkan masyarakat dan bangsanya. Kurikulum 2013 adalah kurikulum berbasis kompetensi. [7] Kurikulum berbasis kompetensi adalah "outcomes-based curriculum" dan oleh karena itu pengembangan kurikulum diarahkan pada pencapaian kompetensi yang dirumuskan dari SKL. Demikian pula penilaian hasil belajar dan hasil kurikulum diukur dari pencapaian kompetensi.[8] Kurikulum 2013 (Kurtilas) adalah kurikulum yang berlaku dalam Sistem Pendidikan Indonesia. Kurikulum ini merupakan kurikulum tetap diterapkan oleh pemerintah untuk menggantikan Kurikulum-2006 (yang sering disebut sebagai Kurikulum Tingkat Satuan Pendidikan) yang telah berlaku selama kurang lebih 6 tahun. Kurikulum 2013 masuk dalam masa percobaanya pada tahun 2013 dengan menjadikan beberapa sekolah menjadi sekolah rintisan. [9]

Kurikulum 2013 merupakan sebuah pembelajaran yang menekankan pada aspek afektif atau perubahan perilakku dan kompetensi yang ingin dicapai adalah kompetensi yang berimbang antara sikap, keterampilan, dan pengetahuan, disamping cara pembelajarannya yang holistik dan menyenangkan. [10]

\section{Bank Materi}

Bank materi merupakan sekumpulan materi-materi pembelajaran yang terorganisir dan terstruktur agar mudah saat digunakan dan diakses. Materi-materi pembelajaran yang akan digunakan disimpan dalam sebuah tempat dan akan diakses oleh pihak yang bersangkutan. Sama halnya dengan bank soal yang untuk menyimpan kumpulan soalsoal, bank materi menyimpan kumpulan materi-materi pembelajaran. Bank soal mengacu pada proses pengumpulan soal-soal, pemantauan dan penyimpanannya dengan informasi yang terkait sehingga mempermudah pengambilannya untuk merakit soal-soal. [11]

\section{E. Learning Management System}

Konsep e-learning sendiri merupakan pengembangan dari sistem belajar distance learning atau pembelajaran jarak jauh. Jika distance learning tidak menitikberatkan pada pembelajaran berbasis teknologi informasi, maka $e$ - 
learning lebih terfokus pada pembelajaran berbasis teknologi informasi. Untuk menunjang perkembangan elearning beberapa perusahaan telah memfasilitasinya dengan menyediakan learning management system. Learning Management System atau biasa dikenal dengan sebutan LMS memungkinkan penyelenggara pendidikan bisa dengan mudah menerapkan e-learning pada lembaganya. Perkembangan e-learning di Indonesia memang sudah cukup pesat, banyak lembaga pendidikan yang ikut mengadopsi e-learning. Namun demikian perkembangan LMS oleh para developer lokal di Indonesia tidaklah cukup membanggakan. Hal tersebut dikarenakan kurangnya LMS lokal yang diciptakan oleh pengembang di Indonesia. [12]

LMS adalah suatu perangkat lunak atau software untuk keperluan administrasi, dokumentasi, laporan sebuah kegiatan, kegiatan belajar mengajar dan kegiatan secara online (terhubung ke internet), E-learning dan materimateri pelatihan. Dan semua itu dilakukan dengan online. [13] Dengan kata lain, LMS merupakan aplikasi yang dapat digunakan dalam sebuah pembelajaran yang bersifat elektronik yang berisi fitur-fitur yang mendukung dalam proses pembelajaran sehingga mampu menyampaikan konten pembelajaran secara cepat dan tepat kepada penggunanya. Sebuah software dapat dikatakan menjadi suatu LMS jika software tersebut mampu melakukan halhal berikut :

- Menggunakan layanan self-service dan self-guided

- Mengumpulkan dan menyampaikan konten pembelajaran dengan cepat

- Memiliki platform yang dapat berbasis "web scalable"

- Mendukung portabilitas dan standar personalisasi isi dan memungkinkan penggunaan kembali pengetahuan.

\section{F. Usability Testing}

Secara umum Usability adalah tingkat kualitas dari sistem (perangkat lunak) yang mudah dipelajari, mudah digunakan dan mendorong pengguna untuk menggunakan sistem sebagai alat bantu positif dalam menyelesaikan tugas, hal ini berpengaruh besar terhadap user experience (UX). Pengujian ini dilakukan dengan harapan mencapai tujuan dimana pengguna yang akan menggunakan aplikasi bisa menggunakan aplikasi dengan mudah serta efektif dalam mencapai penggunaan aplikasi yang optimal. Pengujian Usability dijadikan sebagai ukuran kualitas pengalaman pengguna ketika berinteraksi dengan produk atau sistem apakah situs web, aplikasi perangkat lunak, teknologi bergerak , maupun peralatan-peralatan lain yang dioperasikan oleh pengguna. [14] Usability Testing itu sendiri adalah cara untuk mengevaluasi sebuah produk dengan cara mengujinya kepada calon pengguna. Umumnya, selama pengujian, pengguna akan mencoba untuk menyelesaikan tugas yang diberikan, sementara pemilik produk akan mengamati, mendengar, dan mencatat temuan. Tujuan dari Usability Testing adalah mencari permasalahan kegunaan, mengumpulkan data kualitatif dan kuantitatif, serta menentukan kepuasan pengguna dengan produk tersebut. Berikut merupakan aspek-aspek dari Usability[15] :

- Kemudahan (learnability) didefinisikan pengguna mahir dalam menggunakan sistem serta kemudahan dalam penggunaan menjalankan suatu fungsi serta apa yang pengguna inginkan dapat meraka dapatkan

- Efisiensi (efficiency) didefenisikan sebagai sumber daya yang dikeluarkan guna mencapai ketepatan dan kelengkapan tujuan.

- Mudah diingat (memorability) didefinisikan bagaimana kemapuan pengguna mempertahankan pengetahuannya setelah jangka waktu tertentu, kemampuan mengngat didapatkan dari peletakkan menu yang selalu tetap.

- Kesalahan dan keamanan (errors) didefinisikan berapa banyak kesalahan-kesalahan apa saja yang dibuat pengguna, kesalahan yang dibuat pengguna mencangkup ketidaksesuaian apa yang pengguna pikirkan dengan apa yang sebenarnya disajikan oleh sistem.

- Kepuasan (satisfaction) didefinisikan kebebasan dari ketidaknyamanan, dan sikap positif terhadap penggunaan produk atau ukuran subjektif sebagaimana pengguna merasa tentang penggunaan sistem.

\section{PERANCANGAN APLIKASI}

\section{A. Arsitektur Sistem}

Desain arsitektur system ditunjukkan pada gambar 1.

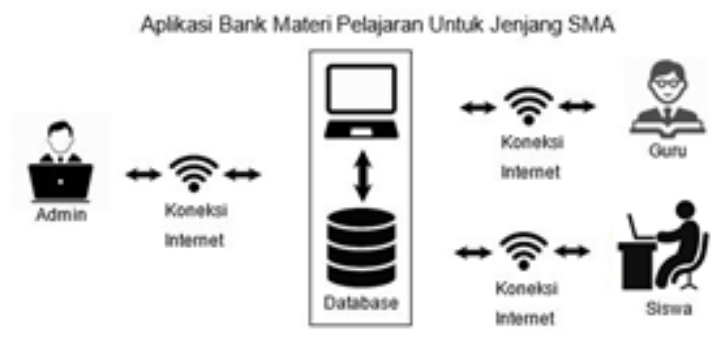

Gambar 1. Arsitektur sistem

Guru akan mengunggah materi pembelajaran, data tersebut akan tersimpan ke dalam database. Siswa akan mengakses materi pembelajaran yang telah diunggah sebelumnya. Admin akan mengelola data-data yang masuk ke dalam aplikasi.

\section{B. Antarmuka Aplikasi}

Struktur antarmuka aplikasi ditunjukkan pada gambar 2 


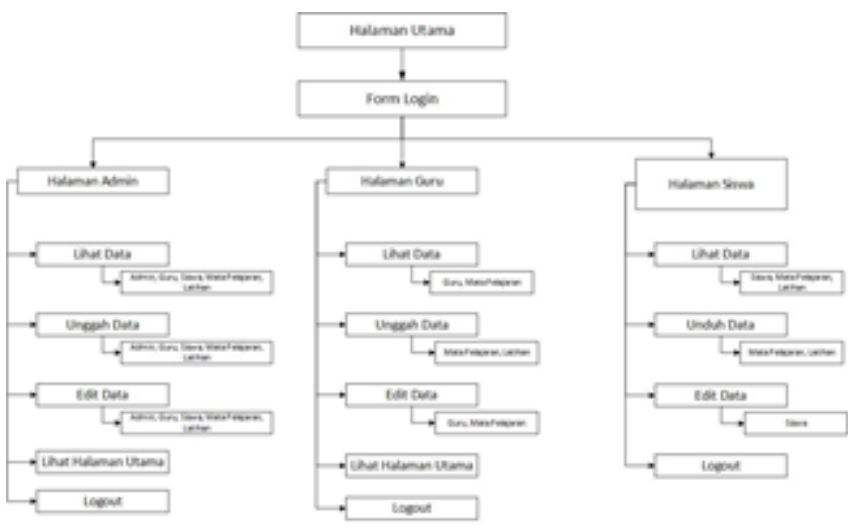

Gambar 2. Antarmuka aplikasi

Aplikasi yang dirancang memiliki 3 halaman berdasarkan hak akses, yaitu halaman admin, halaman guru dan halaman siswa. Sebelum masuk ke halaman masing-masing, pengguna harus melakukan login. Setelah melakukan login, pengguna akan masuk ke halaman masing-masing berdasarkan hak akses.

Pada halaman admin, admin dapat mengelola data-data yang ada di dalam aplikasi. Admin dapat mengedit data pribadi admin, melihat, menginput, mengedit dan menghapus data guru, data siswa dan data pembelajaran. Pada halaman guru, guru dapat mengunggah dan mengedit materi pembelajaran yang dibuat serta mengedit data pribadi. Pada halaman siswa, siswa dapat mengunduh materi pembelajaran yang tersedia, serta mengedit data pribadi.

\section{Pengujian Aplikasi}

Pengujian aplikasi menggunakan Usability Testing, responden akan menggunakan aplikasi dengan menjalankan task atau tugas-tugas yang diberikan. [16] Kemudian responden akan menjawab kuesioner menggunakan aspek-aspek yang ada dalam Usability sebagai poin-poin dalam penilaian kuesioner. Task atau tugas yang akan dikerjakan dapat dilihat pada tabel I dan tabel II. Kuesioner Usability dapat dilihat pada tabel III.

TABEL I

TUGAS SISWA

\begin{tabular}{|l|l|}
\hline No & \multicolumn{1}{|c|}{ Task / Tugas } \\
\hline 1 & Melakukan Sign Up \\
\hline 2 & Melakukan Login \\
\hline 3 & Melihat mata pelajaran Fisika kelas X \\
\hline 4 & $\begin{array}{l}\text { Melakukan download materi kelas X Mata Pelajaran Fisika } \\
\text { Bab Pengukuran Subbab Besaran dan Satuan }\end{array}$ \\
\hline 5 & Melakukan Logout \\
\hline
\end{tabular}

TABEL III

TUGAS GURU

\begin{tabular}{|l|l|}
\hline No & \multicolumn{1}{|c|}{ Task / Tugas } \\
\hline 1 & Melakukan Sign Up \\
\hline 2 & Melakukan Login \\
\hline 3 & Mengunggah satu materi pembelajaran \\
\hline 4 & Melihat daftar materi pembelajaran \\
\hline 5 & Mengedit data materi pembelajaran \\
\hline 6 & Menghapus materi pembelajaran \\
\hline 7 & Melakukan Logout \\
\hline
\end{tabular}

TABEL IIIII

KUESIONER USABILITY

\begin{tabular}{|c|c|c|c|}
\hline \multirow[t]{2}{*}{ No } & \multirow[t]{2}{*}{ Pertanyaan } & \multicolumn{2}{|c|}{$\begin{array}{c}\text { Jawaban } \\
\text { Responden }\end{array}$} \\
\hline & & Ya & Tidak \\
\hline \multicolumn{4}{|c|}{ Learnability } \\
\hline 1 & $\begin{array}{l}\text { Apakah tampilan antarmuka sudah } \\
\text { terlihat baik? }\end{array}$ & & \\
\hline 2 & $\begin{array}{l}\text { Apakah kombinasi warna dan tulisan } \\
\text { dalam aplikasi mudah dipahami dan } \\
\text { dibaca? }\end{array}$ & & \\
\hline 3 & $\begin{array}{l}\text { Apakah menu-menu yang ada di aplikasi } \\
\text { mudah untuk dipahami? }\end{array}$ & & \\
\hline 4 & $\begin{array}{l}\text { Apakah anda dapat melakukan } \\
\text { pengunduhan / pengunggahan materi } \\
\text { pelajaran? }\end{array}$ & & \\
\hline \multicolumn{4}{|c|}{ Efficiency } \\
\hline 1 & $\begin{array}{l}\text { Apakah mudah dalam mengakses materi } \\
\text { pelajaran yang diinginkan? }\end{array}$ & & \\
\hline 2 & $\begin{array}{l}\text { Apakah materi pelajaran yang diunduh / } \\
\text { diunggah sesuai dengan materi pelajaran } \\
\text { yang dipilih? }\end{array}$ & & \\
\hline \multicolumn{4}{|c|}{ Memorability } \\
\hline 1 & $\begin{array}{l}\text { Apakah mudah untuk mengingat nama } \\
\text { aplikasi ? }\end{array}$ & & \\
\hline 2 & $\begin{array}{l}\text { Apakah mudah untuk mengingat } \\
\text { navigasi dalam aplikasi? }\end{array}$ & & \\
\hline 3 & $\begin{array}{l}\text { Apakah anda mengingat cara untuk } \\
\text { melakukan sign up? }\end{array}$ & & \\
\hline \multicolumn{4}{|c|}{ Error } \\
\hline 1 & $\begin{array}{l}\text { Apakah menemukan halaman yang tidak } \\
\text { bisa dibuka? }\end{array}$ & & \\
\hline 2 & $\begin{array}{l}\text { Apakah terjadi kesalahan saat } \\
\text { melakukan login? }\end{array}$ & & \\
\hline 3 & $\begin{array}{l}\text { Apakah terjadi kesalahan navigasi saat } \\
\text { memilih mata pelajaran? }\end{array}$ & & \\
\hline \multicolumn{4}{|c|}{ Satisfaction } \\
\hline 1 & $\begin{array}{l}\text { Apakah akan menggunakan kembali } \\
\text { aplikasi ini jika tersedia? }\end{array}$ & & \\
\hline 2 & $\begin{array}{l}\text { Apakah aplikasi dapat membantu } \\
\text { mempermudah dalam hal } \\
\text { pembelajaran? }\end{array}$ & & \\
\hline 3 & $\begin{array}{l}\text { Apakah memiliki perasaan puas setelah } \\
\text { mengakses aplikasi pembelajaran ini ? }\end{array}$ & & \\
\hline
\end{tabular}

Keterangan Tabel III:

- Pertanyaan

Pertanyaan merupakan pertanyaan yang diajukan dan akan dijawab oleh partisipan pengujian. Pertanyaan terbagi menjadi beberapa kategori berdasarkan aspek Usability.

- Jawaban Responden Jawaban Responden merupakan jawaban yang akan diberikan oleh partisipan pengujian dalam menjawab pertanyaan yang telah disediakan. 
Jawaban yang tersedia adalah jawaban "Ya" dan "Tidak". Jawaban "Ya" mengandung nilai 1 pada bagian Learnability, Efficiency, Memoriability dan Satisfaction. Sedangkan pada bagian Error, jawaban "Tidak" mengandung nilai 1. Nilai-nilai ini akan digunakan pada bagian pengolahan perhitungan data Usability.

Untuk perhitungan bobot nilai dari kuesioner tersebut dapat digunakan dengan persamaan 1 :

$$
\text { Skor }=\frac{\text { Jumlah jawaban bernilai } 1}{\text { Jumlah responden }} \times 100 \%
$$

Skor merupakan hasil dari jumlah jawaban bernilai 1 pada kuesioner dibagi dengan jumlah responden dan dikalikan dengan $100 \%$.

Jika telah didapat nilai maka data akan dibandingkan dengan table kuantitatif perhitungan kuesioner Usability pada tabel IV. [17]

TABEL IVV

TABEL KUANTITATIF PERHITUNGAN USABILITY

\begin{tabular}{|c|c|c|}
\hline Skor & Kualifikasi & Hasil \\
\hline $85-100 \%$ & Sangat Baik & Berhasil \\
\hline $65-84 \%$ & Baik & Berhasil \\
\hline $55-64 \%$ & Kurang & Tidak Berhasil \\
\hline $0-54 \%$ & Sangat Kurang & Tidak Berhasil \\
\hline
\end{tabular}

Keterangan Tabel IV:

- Skor

Skor merupakan nilai persentase dan sebagai tolak ukur keberhasilan dari pengujian yang dilakukan.

- Kualifikasi

Kualifikasi merupakan nilai komparasi berdasarkan skor. Kualifikasi menjelaskan hasil dari skor yang berupa persentase menjadi suatu nilai yang dapat dikategorikan.

- Hasil

Hasil merupakan kategori yang menjadi tolak ukur berdasarkan skor yang telah didapat. Menunjukkan berhasil tidaknya pengujian yang dilakukan.

\section{HASIL PERANCANGAN DAN ANALISIS}

\section{A. Implementasi}

Aplikasi terdiri dari beberapa bagian, yang dibagi berdasarkan tiga hak akses, yaitu Admin, Guru dan Siswa. Halaman Utama yang menampilkan konten dan menu utama dari aplikasi, yaitu akses pembelajaran dan latihan, Halaman Admin, dimana admin dapat mengelola seluruh data yang ada di dalam aplikasi. Halaman Guru, halaman untuk guru melakukan pengunggahan data materi pembelajaran. Halaman Siswa, untuk melihat dan mengubah data pribadi siswa. Halaman Pembelajaran, yaitu halaman untuk memilih mata pelajaran yang akan diunduh. Halaman Latihan, yaitu halaman untuk memilih latihan soal yang akan diunduh. Halaman utama dapat dilihat pada gambar 3 .

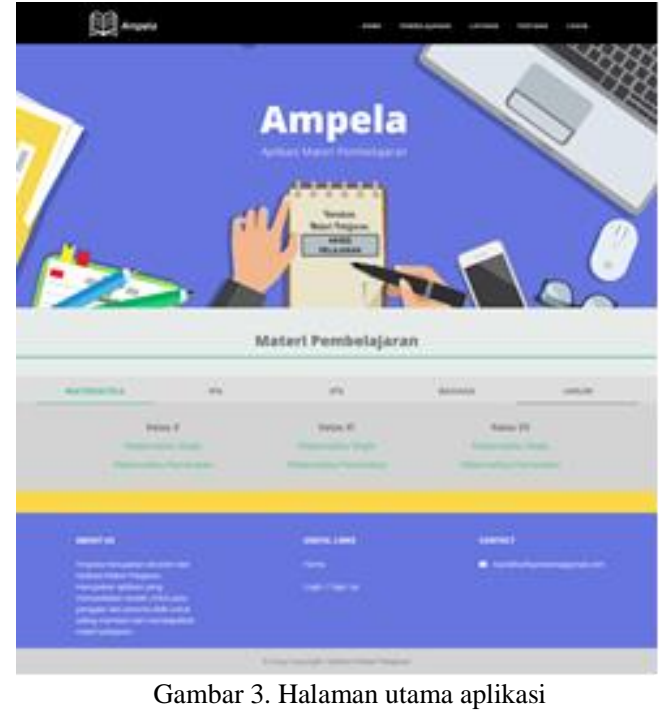

Halaman utama terdiri dari beberapa menu, yaitu Home, Pembelajaran, Latihan, Tentang dan Login. Untuk halaman Login dapat dilihat pada gambar 4.
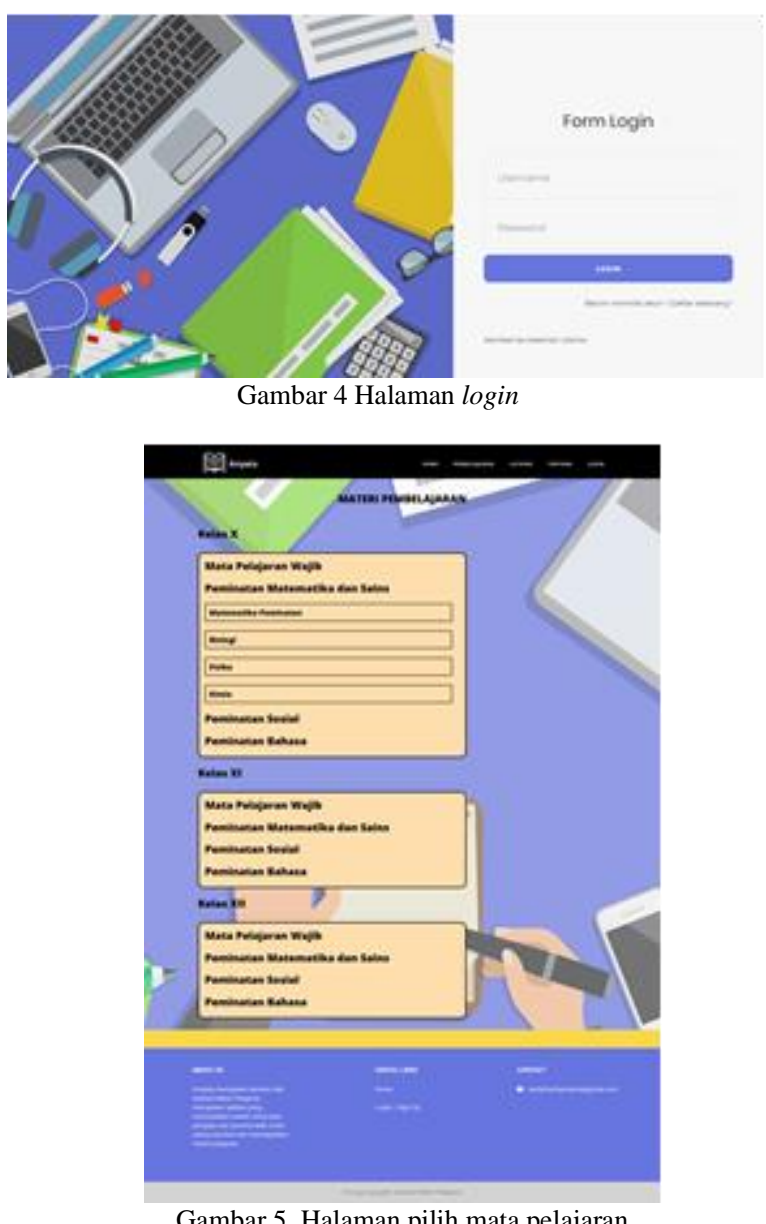

Gambar 5. Halaman pilih mata pelajaran 

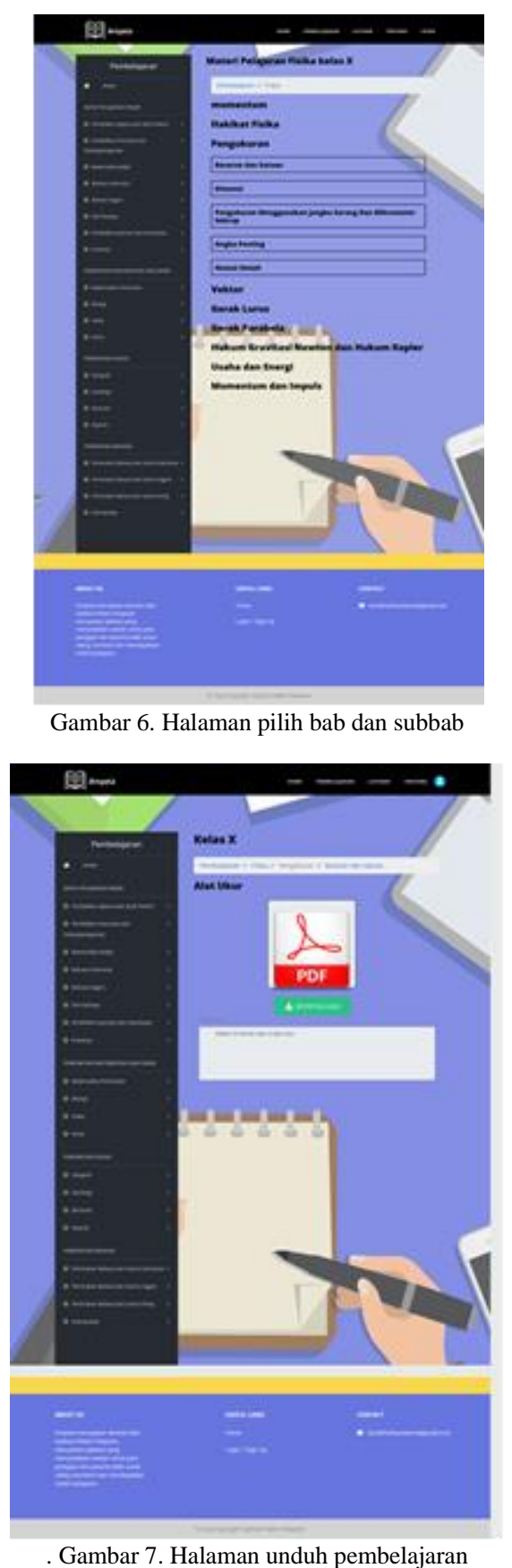

\section{Hasil Uji Aplikasi}

Pengolahan hasil uji aplikasi menggunakan kuesioner dengan aspek Usability dari 15 responden, yaitu 10 siswa dan 5 guru, dapat dilihat pada tabel V dan VI.
TABEL V

Tabel Hasil Pengolahan Kuesioner Siswa

\begin{tabular}{|c|c|c|c|c|}
\hline No. & $\begin{array}{c}\text { Pertanyaan } \\
\text { (Kode) }\end{array}$ & Skor (\%) & Kualifikasi & Hasil \\
\hline \multicolumn{5}{|c|}{ Learnability } \\
\hline 1. & L1 & 100 & Sangat Baik & Berhasil \\
\hline 2. & L2 & 90 & Sangat Baik & Berhasil \\
\hline 3. & L3 & 80 & Baik & Berhasil \\
\hline 4. & L4 & 100 & Sangat Baik & Berhasil \\
\hline \multicolumn{2}{|c|}{ Rata-rata (\%) } & 92.5 & Sangat Baik & Berhasil \\
\hline \multicolumn{5}{|c|}{ Efficiency } \\
\hline 1. & Ef1 & 100 & Sangat Baik & Berhasil \\
\hline 2. & Ef2 & 90 & Sangat Baik & Berhasil \\
\hline \multicolumn{2}{|c|}{ Rata-rata (\%) } & 85 & Sangat Baik & Berhasil \\
\hline \multicolumn{5}{|c|}{ Memorability } \\
\hline 1. & M1 & 90 & Sangat Baik & Berhasil \\
\hline 2. & M2 & 70 & Baik & Berhasil \\
\hline 3. & M3 & 100 & Sangat Baik & Berhasil \\
\hline \multicolumn{2}{|c|}{ Rata-rata (\%) } & 86.6 & Sangat Baik & Berhasil \\
\hline \multicolumn{5}{|c|}{ Error } \\
\hline 1. & Er1 & 90 & Sangat Baik & Berhasil \\
\hline 2. & Er2 & 90 & Sangat Baik & Berhasil \\
\hline 3. & Er3 & 80 & Baik & Berhasil \\
\hline \multicolumn{2}{|c|}{ Rata-rata (\%) } & 86.6 & Sangat Baik & Berhasil \\
\hline \multicolumn{5}{|c|}{ Satisfaction } \\
\hline 1. & S1 & 90 & Sangat Baik & Berhasil \\
\hline 2. & S2 & 100 & Sangat Baik & Berhasil \\
\hline 3. & S3 & 90 & Sangat Baik & Berhasil \\
\hline \multicolumn{2}{|c|}{ Rata-rata (\%) } & 93.3 & Sangat Baik & Berhasil \\
\hline
\end{tabular}

TABEL VI

Tabel Hasil Pengolahan Kuesioner Guru

\begin{tabular}{|c|c|c|c|c|}
\hline No. & $\begin{array}{c}\text { Pertanyaan } \\
\text { (Kode) }\end{array}$ & Skor $(\%)$ & Kualifikasi & Hasil \\
\hline \multicolumn{5}{|c|}{ Learnability } \\
\hline 1. & L1 & 100 & Sangat Baik & Berhasil \\
\hline 2. & $\mathrm{~L} 2$ & 100 & Sangat Baik & Berhasil \\
\hline 3. & L3 & 100 & Sangat Baik & Berhasil \\
\hline 4. & L4 & 100 & Sangat Baik & Berhasil \\
\hline \multicolumn{2}{|c|}{ Rata-rata (\%) } & 100 & Sangat Baik & Berhasil \\
\hline \multicolumn{5}{|c|}{ Efficiency } \\
\hline 1. & Ef1 & 100 & Sangat Baik & Berhasil \\
\hline 2. & Ef2 & 100 & Sangat Baik & Berhasil \\
\hline \multicolumn{2}{|c|}{ Rata-rata $(\%)$} & 100 & Sangat Baik & Berhasil \\
\hline \multicolumn{5}{|c|}{ Memorability } \\
\hline 1. & M1 & 60 & Cukup & $\begin{array}{c}\text { Tidak } \\
\text { Berhasil }\end{array}$ \\
\hline 2. & M2 & 100 & Baik & Berhasil \\
\hline 3. & M3 & 100 & Sangat Baik & Berhasil \\
\hline \multicolumn{2}{|c|}{ Rata-rata (\%) } & 86.6 & Sangat Baik & Berhasil \\
\hline \multicolumn{5}{|c|}{ Error } \\
\hline 1. & Er1 & 100 & Sangat Baik & Berhasil \\
\hline 2. & Er2 & 80 & Baik & Berhasil \\
\hline 3. & Er3 & 100 & Sangat Baik & Berhasil \\
\hline \multicolumn{2}{|c|}{ Rata-rata (\%) } & 93.3 & Sangat Baik & Berhasil \\
\hline \multicolumn{5}{|c|}{ Satisfaction } \\
\hline 1. & S1 & 100 & Sangat Baik & Berhasil \\
\hline 2. & S2 & 100 & Sangat Baik & Berhasil \\
\hline 3. & S3 & 80 & Baik & Berhasil \\
\hline \multicolumn{2}{|c|}{ Rata-rata (\%) } & 93.3 & Sangat Baik & Berhasil \\
\hline
\end{tabular}

Keterangan Tabel V dan VI:

- Pertanyaan

Pertanyaan merupakan pertanyaan yang diajukan dalam pengujian.

- Skor 
Skor merupakan hasil perhitungan yang dilakukan yang didapat setelah melakukan pengujian dengan kuesioner terhadap responden pengujian. Perhitungan skor didapat dengan cara mengambil jawaban-jawaban responden yang mengandung nilai 1 dari kuesioner aspek Usability. Lalu membagi jumlah skor dengan jumlah responden dan mengalikan nya dengan $100 \%$.

- Kualifikasi

Kualifikasi merupakan nilai komparasi berdasarkan skor. Kualifikasi menjelaskan hasil dari skor yang berupa persentase menjadi suatu nilai yang dapat dikategorikan.

- Hasil

Hasil merupakan kategori yang menjadi tolak ukur berdasarkan skor yang telah didapat. Menunjukkan berhasil tidaknya pengujian yang dilakukan.

\section{E. Analisis Hasil Uji}

Berdasarkan hasil pengujian aplikasi, analisis yang didapat adalah sebagai berikut

1. Berdasarkan tabel $\mathrm{V}$, didapatkan nilai rata-rata hasil pengujian Usability bagian Siswa, aspek Learnability diperoleh nilai 92.5\%, aspek Efficiency diperoleh nilai 85\%, aspek Memorability diperoleh nilai $86.6 \%$, aspek Error diperoleh nilai $86.6 \%$ dan aspek Satisfaction diperoleh nilai $93.3 \%$. Apabila dicocokkan dengan tabel kuantitatif perhitungan pada tabel 4.18, maka seperti ditunjukkan oleh tabel hasil pengolahan data kuesioner Usability siswa, secara aspek Usability aplikasi materi pembelajaran yang dibuat mendapatkan kualifikasi "SANGAT BAIK".

2. Berdasarkan tabel VI, didapatkan nilai rata-rata hasil pengujian Usability bagian Guru, aspek Learnability diperoleh nilai 100\%, aspek Efficiency diperoleh nilai 100\%, aspek Memorability diperoleh nilai $86.6 \%$, aspek Error diperoleh nilai $93.3 \%$ dan aspek Satisfaction diperoleh nilai 93.3\%. Apabila dicocokkan dengan tabel kuantitatif perhitungan pada tabel 4.18 , maka seperti ditunjukkan oleh tabel hasil pengolahan data kuesioner Usability guru, secara aspek Usability aplikasi materi pembelajaran yang dibuat mendapatkan kualifikasi "SANGAT BAIK".

\section{KESIMPULAN}

Berdasarkan hasil uji dan analisis hasil uji, maka dapat disimpulkan bahwa :

1. Aplikasi Bank Materi Pembelajaran untuk Jenjang SMA dapat menjadi wadah yang menampung materi-materi pembelajaran.

2. Hasil dari Usability Testing mendapatkan kualifikasi "Sangat Baik" dari pihak siswa maupun guru.

Hasil dari Usability Testing dapat disimpulkan bahwa berdasarkan kuesioner aspek Usability siswa dan guru menilai aplikasi yang dibuat dapat mempermudah proses pembelajaran

\section{DAFTAR PUSTAKA}

[1] KBBI, 2018. Kamus Besar Bahasa Indonesia (KBBI). [Online] Available at: http://kbbi.web.id/didik.

[2] Prihartini, Effiyati. 2017. Pengaruh Metode Pembelajaran dan Minat Belajar Terhadap Hasil Belajar IPA. Jurnal Formatif 7(2): 171-179, 2017.

[3] Kusnadi. 2017. Model Inovasi Pendidikan Dengan Strategi Implementasi Konsep Dare to be Different. Universitas Galuh Ciamis.

[4] Heriyanto, Budi. 2015. Rancang Bangun Sistem Aplikasi Manajemen Soal Pada Bimbingan Belajar PRIMAGAMA (Studi Kasus PRIMAGAMA Pontianak). Jurnal Sistem dan Teknologi Informasi (JUSTIN) Vol. 3, No. 2, 2015.

[5] Undang-Undang Nomor 20 Tahun 2003 tentang Sistem Pendidikan Nasional Pasal 2, ayat 1.

[6] Dewi, Eri Ratna. 2018. Metode Pembelajaran Modern Dan Konvensional Pada Sekolah Menengah Atas. PEMBELAJAR: Jurnal Ilmu Pendidikan, Keguruan, dan Pembelajaran Volume 2 Nomor 1 April 2018 hal 44-52.

[7] Ulhaq, Zia. 2017. Pembelajaran Sejarah Berbasis Kurikulum 2013 di SMA Kotamadya Jakarta Timur. Jurnal Pendidikan Sejarah.. Universitas Negeri Jakarta.

[8] Kemendikbud, 2014. Konsep dan Implementasi Kurikulum 2013. [Online] Available at: https://www.kemdikbud.go.id/kemdikbud/dokumen/Paparan/Papa ran\%20Wamendik.pdf

[9] Mutia, Intan, Herlinda dan Atikah. 2017. Perancangan Knowledge Management System (KMS) Kurikulum 2013 Menggunakan Model Tiwana dan Zack. Jurnal Edukasi dan Penelitian Informatika (JEPIN) Vol. 3, No. 2, 2017.

[10] Amri, S. 2013. Pengembangan \& Model Pembelajaran dalam Kurikulum 2013. Jakarta: PT Prestasi Pustakaraya.

[11] Thorndike, R.L. 1982. Applied Psychometrics. Boston : Houghton Mifflin.

[12] Muhammad, Taofik. 2017. Perancangan Learning Management System Menggunakan Konsep Computer Supported Collaborative Learning. Jurnal Produktif Vol 1 Edisi Juli 2017.

[13] Ellis, Ryann K. 2009. Field Guide to Learning Management Systems. [Online] Available at: http://www.astd.org/NR/rdonlyres/12ECDB99-3B91-403E-9B157E597444645D/23395/LMS_fieldguide_20091.pdf.

[14] Aries, Topan Maulana, Ahmad Yani Ranius dan Nurul Adha Oktarini Saputri.. 2017. Usability Testing Untuk Mengukur Penggunaan Website STIK Bina Husada Palembang. Universitas Bina Darma Palembang..

[15] Nielsen, Jacob. 2011. Usability 101: Introduction to Usability. [Online]. Available at: http://useit.com/alertbox/20030825.html/.

[16] Krug, Steve. 2006. Don't Make Me Think! A Common Sense Approach to Web Usability. California: New Riders.

[17] Arikunto, S. 2009. Prosedur Penelitian Suatu Pendekatan Praktik. Edisi Revisi 6. Jakarta : Rineka Cipta. 